\title{
GENERATIONS OF BOOKS: A TASMANIAN FAMILY LIBRARY, 1816-1994
}

\author{
Patrick Buckridge ${ }^{1}$
}

Woolmers Estate, near the town of Longford in northern Tasmania, was the home of the original Tasmanian branch of the Archer family whose head, Thomas, first settled there in 1816. It was occupied, in turn, by six generations of Thomas Archers, the last of whom died in 1994 without issue. During that 180-year period, a library of some one thousand books accumulated, and these were dispersed throughout the house, giving the appearance of an "endogenous" family library, embodying a process of civilized cultural dialogue across the generations. Closer inspection of the books suggests, however, that the library is a more complicated "exogenous" entity than this, assembled in part from the remains of another family library, perhaps to produce an effect of dynastic cultural distinction in the last two Archer generations.

"I am astonished," said Miss Bingley, "that my father should have left so small a collection of books. - What a delightful library you have at Pemberley, Mr. Darcy!"

"It ought to be good," he replied, "it has been the work of many generations."

"And then you have added so much to it yourself, you are always buying books."

"I cannot comprehend the neglect of a family library in such days as these." [1, p. 32]

Darcy's two responses to Miss Bingley's compliments convey not just personal irritation but also a larger worry that "in such days as these" the worth of long-established and well-stocked family libraries is being vulgarly estimated in terms of the wealth and social prominence they represent rather than their accumulated power for good. Whether that good chiefly

1. Associate professor, School of Arts, Media, and Culture, Griffith University, Nathan QLD 4111, Australia. Telephone 07-373-57165; E-mail P.Buckridge@griffith.edu.au.

[Library Quarterly, vol. 76, no. 4, pp. 388-402]

(C) 2006 by The University of Chicago. All rights reserved. 0024-2519/2006/7604-0005\$10.00 
consists, for Mr. Darcy, in preserving traditional social hierarchies or in underwriting a more active social benevolence is not apparent to the reader at this early stage of the novel, but it is at least clear that his conception of the family library has an idealistic dimension that is entirely absent from Miss Bingley's. Such a dimension is usually also absent from advisory articles about the family library as part of the decor of the modern middle-class home, an enduring topic of interest in lifestyle magazines and mail-order catalogs, archly evoked by Nicholson Baker some years ago in his essay on "books as furniture": "It's undeniable that books furnish a room, and it's nothing to be ashamed of. They require furniture, in the form of bookshelves, but they are themselves furniture as well. 'No furniture so charming as books, even if you never open them, or read a single word'-so Sydney Smith, one of the founders of the Edinburgh Review, and a devoted Victorian reader, told his daughter as they had breakfast in his library" [2, p. 195].

There has been relatively little serious discussion of the family library as a social institution distinct from public libraries, on the one hand, which are designed-or have evolved-to serve larger reading communities, from nations to workplaces, and from personal libraries, on the other hand, which reflect the interests of single individuals. Most published research on the subject has consisted of either bibliographic reconstructions of important family libraries or historical accounts of the sale and dispersal of aristocratic family libraries [3-4]; the known contents of family libraries have been used as evidence of class or gender "mentalities" existing at particular times and places [5-6]. ${ }^{2}$ An exception is the work of Ronald J. Zboray and Mary Saracino Zboray, whose work on readership in antebellum New England includes an instance of virtual communication across two generations of readers within a family by way of the books in the family library [8].

Generally speaking, though, it remains true that the family library, understood as the ordinary, small- to medium-sized book collection, acquired and used by several family members, usually over two or three generations, has been oddly invisible to historians of reading. And yet, it would not be especially reckless to say that most adults living in the developed world today either live with, or once lived with, a family library of this kind. They are simply "the books in the house"-those things that are inherited, exhibited, packed away, added to, sold, lent, borrowed, picked up, put down, read, written in, given away, and used to tilt the slide projector to the right angle-and their apparent invisibility is no doubt largely a function of their inseparability from the ordinary business of living.

The family library, in this sense, constitutes a real and distinct social

2. For a discussion of the reconstructions of important family libraries, see Germaine Warkentin's work on the Sidney family library at Penshurst [7, pp. 1394-411]. 
deployment of books and, as such, it should be of interest to historians of reading even when, as in the case to be discussed, the collection itself is not especially large, valuable, or unusual. This article is an attempt to say something coherent about this particular type of deployment, using as a case study a small- to middle-sized Australian library dating back to the early nineteenth century: a family library unremarkable for size and content but unusual in the circumstances of its preservation in ways that promise to highlight its dynamics as an institution. The fact that it is now no longer a functioning family library but a heritage site-that its dynamics are, in effect, frozen-may even lend them greater visibility.

In a stimulating and wide-ranging essay on the cultural history of the Australian colonies in the nineteenth century, Simon During suggested that for much of that period a "civilizing process" was occurring that might best be understood as a series of failed attempts to create a "modern literary subjectivity," defined as "a heightened capacity to respond to real-life events as if they were occurring in fiction or poetry," which he sees as crucial to the historical formation of secular liberalism in the Romantic period [9, p. 4]. On this view, various sections of colonial society, at different times and places and by various institutional means, made efforts, which they themselves usually regarded as unsuccessful, to import, engraft, implant, or translate-the metaphors also varied-"civilized" ethical dispositions capable of resisting the potentially brutalizing and corrupting effects of life in the colonies and of ensuring moral and political progress [9, p. 4]. This "macro" perspective on nineteenth-century culture in Australia provides a useful framework in which to view the "micro" cultural phenomenon I am about to discuss and may point to some larger meanings and relations.

The library in question is housed at Woolmers, near the town of Longford in northern Tasmania. The unusual feature of the library is that it has accumulated over six generations of the one family, the Archers, who owned Woolmers from 1816 to 1994, when the last of six Thomas Archers died without issue, having bequeathed the property to a private family trust, the Woolmers Foundation, through which members of the extended Archer family now run the estate as a heritage site. The main house, first erected in 1819 of timber with brick nogging and extended outward and upward in brick during the 1830s, is now a sprawling, two-level structure constructed around a central courtyard. The internal restoration is advanced but incomplete, and some bedrooms on the upper level are unrestored and unpowered and hence, unfortunately, off-limits.

The house contains about a thousand volumes in standing bookcases and arranged on tables, pianos, and elsewhere, in seven rooms and hallways on the ground floor, with perhaps half that number again hidden away in various unrestored corners of the upper story. The accessible books were 
examined for inscriptions, marginalia, underscores, side linings, bookmarks, paper spills, uncut pages, pressed flowers, inserted letters, envelopes, newspaper cuttings, and any other signs of use (or nonuse) that might be translatable into a record of the family's reading over the generations. ${ }^{3}$ Of the thousand books inspected, about four hundred had inscribed names (which were taken as evidence of ownership), fifty contained bookmarks of one sort or another, and fifteen contained uncut pages (which was taken as evidence that they had not been read, though, intriguingly, two books-a volume of Froissart's Chronicles [1849] and a volume of the Charles Knight Pictorial Shakspere of 1839-were completely uncut, yet contained bookmarks).

The public face of the Woolmers book collection is the dining room. Here, apart from a few dozen single volumes, there are upward of fortyfive sets of books ranging from two to twenty-seven volumes apiece. They include several multivolume encyclopedias and the complete works of several canonical authors of the eighteenth and early nineteenth centuries, for example, Addison and Steele, Fielding, Smollett, Gibbon, Scott, Burns, and Byron, as well as Shakespeare and the religious controversialist Bishop William Paley. Most of these are certainly books acquired and read by the first Thomas Archer: some bear a purchase date, and many are signed by him (Tho: Archer) on the title page and the last page, a conventional indication that the signatory has completed the journey. The eight volumes of Paley are signed, though not at both ends; some of them contain bookmarks. The same is true of the twenty-seven volumes of the Penny Cyclopaedia and twelve of the Penny Magazine.

The first Thomas Archer (1790-1850) was a respected member of the Tasmanian governing class. The Australian Dictionary of Biography describes him as a generous and progressive employer of free labor and a prominent member of the Legislative Council for many years [11, pp. 25-26]. His obituarist in the Launceston Examiner of October 19, 1850, described him as having an active, inquiring, and intelligent mind, adding that, in the latter years of his life, which were dogged by chronic illness and inactivity, "even those he admitted to closest intimacy were unacquainted with many of the workings of his mind" [12, p. 103]. These observations are useful in countering the impression of the two large portraits of an irascible and domineering country squire, florid and portly, which glare down at the visitor from both ends of the dining room. The obituary suggests precisely what his books also convey: that appearances-perhaps especially official family portraits-can be deceptive and that he may well himself have possessed something of During's "modern literary subjectivity." This Thomas

3. For a comparable use of reading traces to yield evidence of reading habits and intentions, see [10ff.]. 
Archer, we might surmise, was the sort of man who, for all his public prominence and familial authority, bought his books with no more than half an eye to signifying his social position and read them deeply and thoughtfully, if also dutifully and methodically. Indeed, the pride of place accorded to his Penny Cyclopaedias and Magazines might be taken to suggest that knowledge, even in digested and extracted form, was more important to him than the display of fine books for their social cachet.

The most fascinating and unusual feature about Woolmers, at least for a book historian, is the apparently endogenous character of its library, by which I mean its appearance of having grown from within, like the Darcy family library at Pemberley: a "work of many generations." Estates of this kind, most of which are owned and run by the National Trust in Australia, are normally acquired by the Trust after the libraries have been dispersed and are then stocked with suitable-looking volumes from elsewhere; these are obviously of no value in constructing a reading history of the resident family. The Woolmers library seemed to have precisely that potential, and the terms in which the estate is currently promoted as a heritage site for tourists-as representing "a continuous association with the Thomas Archer family, providing an encapsulated record of six generations, and the changes to their lifestyle, from the time the land was first settled circa 1817 to the death of the last heir in 1994"-tend to endorse that expectation. Indeed, the transgenerational designations of the main "book-rooms"master bedroom, "Mrs. Archer's bedroom," breakfast, drawing, and dining rooms-even seemed to hold out the possibility of matching different kinds of reading with those different dimensions of family life, even as family life itself shifted and evolved with the passing of the generations.

It may have been noticed that the various "book-rooms" (listed above) did not include a library or study. There is, in fact, no such dedicated room at Woolmers, and there never has been-though, at one time, there was going to be. In a sequence of events that probably reflects pretty accurately the cultural priorities of the colonial gentry, an impressive pair of walnut bookcases were designed and built for a separate library that was part of the original plan of the house but was abandoned during the building process when funds began to run short. The shelves were subsequently installed in the dining room instead, where they do not quite fit.

As for the first generation, so for the following ones: the endogenous Pemberley model of the ancestral family library as an incrementally growing storehouse of cultural value does not quite fit, either. On the ideal view, one could imagine each successive generation of Archers reading, assimilating, and adding to the books of their forebears, no doubt modifying their relationship to them, as owners and readers, in subtle but interesting ways as they registered and responded to the changing diorama 
of history, yet all the while maintaining a vital continuity across the generations - a continuity that is both embodied and enabled by the concrete reality of the library (qua book collection) itself. It is almost as if the temporal succession of generations could be projected spatially as a simultaneous community of readers in virtual dialogue with one another. Or so the ideal, endogenous model plays out.

There may be some multigenerational family libraries in the world of which all this is true: it is difficult not to hope so. But the Woolmers library is not one of them, and there are three reasons why, upon closer examination, it cannot be. The first is that the house was not continuously occupied by the immediate family, a fact that, at the very least, complicates the picture: for most of the second half of the nineteenth century, Woolmers was either leased to tenants or run by members of the extended family who were living on nearby properties. The second Thomas Archer predeceased his father, who died in 1850, and the third and fourth Thomas Archers and their families lived mainly in Launceston and Melbourne, making only occasional visits to Woolmers.

The second reason for skepticism regarding the endogenous model has to do with the relatively sparse evidence of actual reading, especially across the generations. There is abundant evidence of primary book ownership, which can fairly safely be inferred from inscribed names and bookplates, and there is some evidence-not a great deal—of books being read by those primary owners, but there is very little evidence of books acquired by earlier generations being read by later generations. This is not to assert the contrary, that no such reading took place; it is simply to acknowledge that there are very few indications of it-two or three at most-either in or on the books themselves. And, what evidence there may have been in family letters or diaries does not appear to have survived or is not accessible.

The third reason has to do with the chronological structure of book ownership. The endogenous image of the library tends to assume that the collection was incrementally rather than sporadically augmented, such that the ownership of the books would have been more or less evenly distributed across the six generations. But of the thousand books inspected for this study, almost half had inscriptions or bookplates indicating ownership by a family member and, of these, almost half were owned by the same individual, namely, the wife of the fourth Thomas Archer, Eleanor Mary Archer, née Harrop (1860-1933). A further third was owned by her father, Edward Davy Harrop (1836-91). Of the remaining sixth of the ownerinscribed books, all but a handful were acquired either by the fifth Mrs. Archer, née Marjorie Patten, or by her husband's great-great-grandfather, the first Thomas Archer. The remainder-some fifteen books in all-are inscribed to the fourth and fifth Thomas Archers and are nearly all either school textbooks, school prizes, or gifts. 
This leaves a large number of books of unknown or, at least, unprovable ownership. Some of these are of a recreational or practical nature, directly reflecting the known sporting and travel interests of the fourth Thomas, a champion golfer and inveterate globe-trotter; the farming and motoring interests of the fifth Thomas, who made Woolmers the permanent family residence again, with a working orchard; and the rose-gardening interests of his wife and of their son, the sixth and last Thomas Archer. Most of the unallocated volumes, however, are literary, but some of these too can be assigned an owner with some degree of probability based on a combination of factors-none of which carries much weight by itself, of course-including approximate date of purchase, type of book, and location within the house.

What this partly notional process of allocation reveals is that the library, as it stands, is not so much the endogenous, transgenerational family institution I had imagined it might be but, on the contrary, a largely exogenous accumulation of books, introduced from outside, and answering to the interests of just four main readers, two of whom were Archers by marriage and one of whom was not an Archer at all. After the first Thomas Archer, none of the succeeding ones seem to have been great readers or book lovers.

The structure of the Woolmers collection can usefully be considered as not one but two family libraries, the one embedded within, and to some extent concealed by, the other, and disentangling them can, I think, shed an interesting light on colonial library formation. The inner, embedded library might even be regarded as a family library on the Pemberley model of a transgenerational reading community, though on a much reduced timescale. It is not the Archer family library, however, so much as the Harrop family library. Some further biographical information may be in order at this point.

Edward Davy Harrop was born in England in 1836; married Mary Boothroyd, a Scottish girl, in about 1857; had three daughters; and died in 1891. He was the manager of the Commercial Bank of Launceston and served on the Board of Management of the Launceston Mechanics' Institute for three years (1868-71) [13, p. 148]. As it happens, his membership on the Institute Board coincided with a controversy involving the churches, the newspapers, the institute, and the civic authorities, concerning the very popular "Penny Readings." These readings, performed by a professional troupe of readers and musicians on a variety of political, religious, and literary topics, were being presented at the Institute Hall to large and, at times, rowdy audiences, to the consternation of some members of the board 
and public and to the delight of others [13, pp. 66-71]. (Harrop would certainly have been in the latter, more liberal group.)

Edward Harrop's inscribed books suggest that he was an intellectually active reader and thinker. They also indicate that he purchased his books locally from the Launceston bookseller, J. Walch and Sons, later Walch and Birchall. His early interests embraced natural history, microscopy, and medicine, on which topics he owned several bound journals and books. In belles lettres-apart from some classical translations, a three-volume illustrated Shakespeare, and some books by Dickens, Tennyson, and Bulwer Lytton-there is a lot of De Quincey; several works of the early nineteenthcentury Scottish writer John Wilson, alias "Christopher North," editor of Blackwoods; some eighteenth-century French biographies (in French); and a collection of Renaissance English poetry. (Simon During has pointed to the special importance of De Quincey and Wilson as linked representatives of "the Scottish side of second-generation Romanticism" in Australia [9, p. 8].)

All the signs, however, are that Harrop's strongest interest was in contemporary debates on religion, science, and free thought, and his copies of Arnold's Culture and Anarchy and Literature and Dogma are heavily side ruled, though not annotated. There are also inscribed copies of Henry Atkinson and Harriet Martineau's Letters on the Laws of Man's Nature and Development, a key free-thought text of the 1850s, and of the "notorious" Ingoldsby Legends, which had been embroiled in the Penny Readings furor in Launceston [13, p. 69]. ${ }^{5}$ There is even a copy of Essays and Reviews (1860), the famous collection of skeptical essays on religion that scandalized and polarized Victorian intellectuals as much as Darwin's Origin of Species had done the previous year. It has a press clipping on F. D. Maurice's intervention tipped in.

The parsimonious evidence of the books themselves is supplemented by a fortunate find on the top shelf of the master bedroom, namely, Edward Harrop's commonplace book. Bought in 1859 when he was twenty-three years old, and maintained for three or four years after that, it reveals an exhilarated and curious engagement with the burning issues of that decade in religion, the physical sciences, ancient and modern history, and European politics through his reading, questioning, and

4. No member of the extended Archer family, or of the families of the four other Archer wives, was ever an officeholder or board member of the Launceston Institute throughout its long and active history, a fact that may simply reflect the social distance between the urban middle and working classes and the country gentry.

5. The notoriety was an effect of the anti-Catholic satire of some of the Legends, esp. "The Lady Rohesia," the reading of which caused an uproar. 
transcribing of authors like Darwin, Comte, Layard, Carlyle, Mill, Gibbon, Lyell, Macaulay, Haeckel, Luther, Milton, and Harriet Martineau. His interests extended further again through journals, especially the Westminster Review but also the Intellectual Observer and the Popular Science Review. ${ }^{6}$

The commonplace book reveals something of the individual "reading existence" of the young Edward Harrop. ${ }^{7}$ Some books that he gave and received as gifts help to place that existence in a wider familial context. In September 1864, he received as a birthday gift from his "affectionate Grandmamma" in Manchester, a book on microscopic life forms, A Synopsis of the British Diatomaceae - hardly the kind of gift she would have chosen "on spec" without an awareness of her grandson's scientific interests; the several bookmarks indicate that it was a wise choice. There are also two books of Scottish poetry inscribed by him as gifts to his wife Mary in the early years of their marriage, and there is a glimpse of her parents' reading tastes in an 1835 French edition of Voltaire's Histoire de Charles XII, roi de Suèdes, inscribed "Boothroyd, November 13, 1837." The connection of his life as a reader to the wider Launceston community is visible through his recorded involvement with the local Mechanics Institute in his late thirties.

His daughter Eleanor Mary (or Nellie, as she often inscribes herself) presumably inherited her father's books after his early death in 1891. This was the year after her marriage, at the age of 30, to the fourth Thomas Archer; at some later stage, she must have brought them, together with her own books, to Woolmers, where she and her immediate family seem to have spent some of their time from the late 1890s.

Nellie's reading was remarkably catholic, ranging from the essays of Carlyle and Ruskin to the popular novels of Marie Corelli, Ethel M. Dell, Edgar Wallace, and E. Phillips Oppenheim. It is rich in canonical English writers, particularly of the late eighteenth and nineteenth centuries, and it also includes a number of classic American authors. Cooper, Emerson, Lowell, Thoreau, Hawthorne, Poe, Holmes, Longfellow, Bret Harte, Twain, and Booth Tarkington are all represented by one or more volumes, many with bookmarks and other signs of use. Hawthorne is there only for his "wonder book" of stories for children, which she received as a school prize at age 14, but that may have sown the seed of an interest in American writing that she continued to pursue until she was at least sixty years old.

An interest in Celtic literature-fiction, poetry, and ballads-is also evi-

6. Stephen Colclough provides useful commentaries on two individual English commonplace books of the 1830s [14]. The Harrop commonplace book is more systematic and, unfortunately, more noncommittal than Colclough's examples.

7. The helpful phrase, "reading existance" [sic], is from John Clare's Journal, quoted by Colclough [14, p. 5]. 
dent, which may have come from her mother, whose Scottish bent is attested by her husband's gift to her, and who gave Nellie some Irish books when she was a child. Her father's influence can probably be discerned in her own apparent interest in Carlyle and De Quincey, and in French literature-Rabelais, Molière, and especially Victor Hugo are well represented among her inscribed books (in translation).

Dramatic literature was another enthusiasm: Shakespeare, of course, and there are also editions of comedies by Sheridan, Molière, De Musset, and six volumes of the Mermaid Series of unexpurgated Jacobean plays put out by Havelock Ellis in the 1880s. Tolstoy is there too (the thirteen-volume London edition of 1888), and some Australian fiction and poetry (Henry Kingsley, Adam Lindsay Gordon, and several novels by Rosa Praed).

If there is a core interest manifested in Nellie Archer's books (as there clearly is in her father's), it is not readily apparent what it might be. It would seem that she took some cues from each of her parents-and also from an elder sister who read Coleridge-and expanded her own "serious" reading horizons in various directions partly on that basis, no doubt sometimes constrained by what the Launceston bookshops could provide but more often stimulated by what they advertised. Walch's Literary Intelligencer, a monthly local bookseller's catalog, which also contained some book notes and news of the local cultural scene, seems to account for a majority of purchases.

What kind of a reader was she? Invoking a well-worn and somewhat unsatisfactory duality, I would describe her as an "extensive" reader of the belletristic genres: fiction, poetry, essays, and drama. One book suggests, however, that she made an effort on at least one occasion to emulate her father's more "intensive" reading habit. She owned a small number of duplicates-perhaps a result of frequently shifting residences-and one of her two copies of Sartor Resartus is as heavily side ruled as are his Matthew Arnolds. A year or so later-perhaps to give her some help with the "harder" authors-she bought a book of published lectures on Carlyle, Ruskin, Emerson, and Browning by Joseph Forster. In general, though, her impulse seems to have been the one common to many avid, extensive readers then and now, namely, the lifelong exploration and enjoyment of canonical and contemporary literature, without the consciously self-improving motive characteristic of the intensive male reader of her father's generation.

To the extent that it was a shared reading life, Nellie Harrop Archer seems to have shared it mainly with her parents and sisters. Her husband, the fourth Thomas, seems not to have figured within it. More surprisingly, perhaps, her son-the fifth Thomas-does not seem to have been a large part of it either: of the eight books inscribed by or otherwise assignable to her son, none is a gift from his mother or seems likely to have been 
influenced by her reading preferences. Nor is the wider community context to which her father was connected through the Mechanics Institute evident in his daughter's books. Two books bear a bookplate, "Nil Desperandum," which was a small and select ladies' literary society founded by the governor's wife in the 1880 s, but she is not listed as a member, nor is it likely that she would have been one [15, pp. 147, 149]. There are also three bookplates of the Launceston Circulating Library, of which she may well have been a subscriber, but all three books seem more likely to have been acquired by her as secondhand purchases.

The Harrop books, then, can be imaged as the concealed family library at Woolmers. Taken as a single entity, this library does record traces of half a dozen reading lives connecting and interacting across at least three generations of Boothroyds, Harrops, and Archers-four, if one wanted to stretch a point and include Edward's grandmother in Manchester, who does seem to have maintained a relationship of some kind with her grandson in the colonies. The dominance of the female line in the formation of this multigenerational reading tradition is a fact hardly surprising in itself but worth noting in the context of the patrilineal nomenclature, which is conventional and inevitable for precontemporary family institutions of all kinds, including libraries.

The Harrop library is "concealed" partly by the disposition of its books, as they were arranged by the fifth Mrs. Archer, Marjorie Grace Patten, probably after her husband's parents died in 1933 and 1934. Under this arrangement, most of Nellie's books appear to have been about evenly divided between the generically named "Mrs. Archer's bedroom," and the breakfast and drawing rooms; and most of Edward Harrop's books were shelved in the master bedroom and the breakfast room, with the remainder scattered around the hall bookcases. There are no inscribed books belonging to either of them in the dining room, which houses the main "showcase" collection and which is specifically associated, in Archer family lore, with playing host to visiting royalty, HRH, the Duke of Edinburgh, in 1868 [12, pp. $156-57]{ }^{8}$

The effect of Marjorie's arrangements was to fragment the internal coherence of the Harrop library, relegating the books to the less formal rooms where they became background to the "official" cultural face of the Archer dynasty at Woolmers. What occupies the foreground is what I earlier called the "outer library," a distinct cultural artifact assembled-mainly, I think, during the 1940s-on the basis of a relationship between Marjorie Archer and the books of her husband's great-great-grandfather.

Within this outer library — which is mainly coterminous with the dining room collection-it is fairly certain that many, perhaps all, of the unin- 
scribed books, even those that look rather like Thomas Archer's because of their author, subject, or date of publication (e.g., a two-volume translation of Froissart's Chronicles [1839]) are not his but were bought and shelved beside and between his books a hundred years later by Marjorie Archer. The evidence for this is the number of pre-1800 and early 1800 imprints that are inscribed by her, often with a previous owner's inscription erased-for example, four volumes of Johnson's The Adventurer (1793) and the Tragedies of Sophocles (1813). It seems likely, in fact, that Marjorie developed something of an interest in acquiring eighteenth- and early nineteenth-century editions and used some of them to fill the dining room bookshelves with books that were at least chronologically connected to the founder of the library and the dynasty, with whom she probably shared some, but not many, canonical literary tastes.

Marjorie, the fifth Mrs. Archer, died in 1968. The historian of the extended Archer family, Neil Chick, describes her and her husband, "Old Tom," as "without question genteel folk," noting that she "would wear long dove-grey gloves as she served guests their tea using the priceless silver in the great dining room" [12, p. 159]. She was also, it seems, an impressive repository of Archer family lore and, thus, the kind of person to whom one might plausibly attribute a deliberate and long-term cultural project of this kind. Indeed, she may well have undertaken it in tandem with a parallel project of her husband's, for in these same years, he was busily engaged in reconstituting the estate economically as a residential family farm on the much-reduced acreage left to them after the crown had resumed most of their land under the Closer Settlement Scheme of 1911 [12, p. 158]. What Marjorie's project amounted to, I suggest, was an attempt to bind the Archer family history into a single dynastic narrative of a family whose cultural distinction, exhibited more than a century earlier in the library established by the first colonial generation, would be perpetuated in the apparently endogenous family library belonging to the fifth generation of Archers, her own. ${ }^{9}$ In that process of "restoration," a smaller, but in some respects more genuinely endogenous, family library, that of the Harrops, became grist to the Archers' mill.

The moderately impressive facade of the outer library does, however, for all its apparent inclusiveness, have at least one noticeable gap. Somewhat ironically, in view of the fictional family library to which I initially referred, it seems that the one clearly canonical English author of the eighteenth and nineteenth centuries who is completely unrepresented in the Woolmers library is Jane Austen. It seems a remarkable hole in a

9. I use the term "distinction" without the rigor and complexity of the concept in the work of Pierre Bourdieu but with the intention, simply, of conveying both a social and an aesthetic dimension in combination. 
collection of this size, period, and provenance, and no external explanation comes to mind that would apply, as it would need to do, to both the fourth and the fifth generations of the family. ${ }^{10}$

It seems only fair, finally, to report that Marjorie had a reading existence of her own, quite apart from her putative project for the Archer family library, and this existence is most manifest, as one might expect, in "Mrs. Archer's bedroom." There we find her inscription in several "popular" novels by, among others, Edgar Wallace, Jeffery Farnol, Somerset Maugham, and Nevil Shute; in a few books of a popular mystical bent; and in copies of some of the recent English classics. She seems to have shared her mother-in-law's pleasure in the great English essayists, of whom there are several editions belonging to each woman. Charles Lamb is especially well represented with four different editions of the Essays of Elia, one of which is inscribed by the fifth Thomas, their son and husband-Old Tom, as he was later called-in one of the few traces of a male Archer in the library after 1850 .

There is also evidence-a signed bookmark in chapter 24-that Old Tom sat down on a few occasions in the 1950s to read, and perhaps not finish, Scott's Waverley in an early (1819) but uninscribed nine-volume set. The set was acquired for the dining room, I would guess, by his wife rather than his great-great-grandfather-who did, if the Penny Cyclopaedias are any indication, like to put his name to everything. In any case, Old Tom would thus have read one of the best-known descriptions of a family library in the whole of English literature: "The library at Waverley-Honour, a large Gothic room, with double arches and a gallery, contained such a miscellaneous and extensive collection of volumes as had been assembled together, during the course of two hundred years, by a family which had been always wealthy, and inclined, of course, as a mark of splendour, to furnish their shelves with the current literature of the day, without much scrutiny, or nicety of discrimination" [18, p. 45].

Through this "sea of books," the young Edward Waverley drove "like a vessel without a pilot or a rudder," indiscriminately devouring the classics of English poetry, drama, and chronicle; Italian novelle; French memoir and knightly romance; and much else-forming a "modern literary subjectivity" with a vengeance, and predisposing himself, in the process, to a dangerous attraction to romantic Jacobitism.

There is a double irony here. First, the simple irony, poignant enough

10. Austen's novels were frequently advertised for sale in Tasmania from the 1840s [16, p. 308]. Some light may be shed on Nellie's "blind spot" (but not Marjorie's) by recent work on the size and price of nineteenth-century editions of Austen [17, pp. 245, 364, $578-80]$ 
in its own way, which is contained in the image of Tom Archer, a country gentleman, reading a book in a family library about Edward Waverley, a very different sort of country gentleman in a very different place and time, reading books in a rather similar family library. Much more unsettling than that, however, is the further irony-somewhat at odds with the first—which is that, for all we know, Tom Archer might have been as voracious a reader as Edward Waverley and so, for that matter, might his and Marjorie's son, the sixth Thomas Archer, of whose reading there is literally not a trace but who lived among the books for over seventy years. Avid readers-as distinct from disciplined, intensive, self-improving, or "raid readers"-tend not to annotate, underline, or side rule their books, let alone keep commonplace books. They also (like Edward Waverley, who "read no volume a moment after it ceased to excite his curiosity or interest" [18, p. 45]) leave books unfinished. And if, in addition-having a large family library at their disposal-they do not buy or own many books themselves, then their whole reading existence can pass leaving hardly a trace.

What this article has attempted to do-and the preceding paragraph acknowledges the limits of the project and the provisionality of the findings-is to exploit the fairly minimal reading traces in the Woolmers library, which are often all there is to work with in private libraries of this kind, to infer and specify some of the ways in which a particular book collection might have worked as a "family library" at different points in its history. I have suggested that a large part of the collection might indeed have functioned as the material basis for a transgenerational dialogue on the implicit model of the endogenous family library at Jane Austen's Pemberley but that this part of the collection, the "Harrop family library," was later subsumed, subordinated, and rearranged so as to form part of a longer and more distinguished dynastic narrative artificially embodied in the Archer family library.

These microprocesses can tell us something, perhaps, about the strategies used for reframing and repackaging cultural capital in a postcolonial society and about the range of ways in which a family library can function as a reading institution in such a society. To that extent, they may also offer some material purchase on During's argument regarding the formation of "modern literary subjectivity" in colonial Australia. If Scott's Waverley found the wherewithal to achieve it (for better or worse) in an ancestral family library, then perhaps the last two generations of the Archers, in constructing a fair approximation of an endogenous ancestral library out of largely exogenous materials and in unpropitious circumstances, can at least be credited with creating the conditions for achieving it. What the records cannot tell us with certainty is what kinds of subjectivities were actually formed there or whose they were. 


\section{REFERENCES}

1. Austen, Jane. Pride and Prejudice. Edited by James Kinsley and Frank Bradbrook. Oxford: Oxford University Press, 1985.

2. Baker, Nicholson. The Size of Thoughts: Essays and Other Lumber. London: Chatto \& Windus, 1996.

3. Reid, Peter H. "The Decline and Fall of the British Country House Library." Libraries $\mathcal{E}$ Culture 36, no. 2 (Spring 2001): 345-66.

4. Munby, A. N. L. "The Library." In The Destruction of the Country House, 1875-1975, edited by Roy Strong, Marcus Binney, and John Harris, pp. 106-10. London: Thames \& Hudson, 1974.

5. Davis, Richard Beale. A Colonial Southern Bookshelf: Reading in the Eighteenth Century. Athens: University of Georgia Press, 1979.

6. Hayes, Kevin J. A Colonial Woman's Bookshelf. Knoxville: University of Tennessee Press, 1996.

7. Warkentin, Germaine. "Ins and Outs of the Sidney Family Library." Times Literary Supplement 4315 (December 6, 1985): 1394-411.

8. Zboray, Ronald J., and Saracino, Mary. "Books, Reading and the World of Goods in Antebellum New England." American Quarterly 48, no. 4 (1996): 587-622.

9. During, Simon. "Out of England: Literary Subjectivity in the Australian Colonies, 1788-1867." In Imagining Australia: Literature and Culture in the New New World, edited by Judith Ryan and Chris Wallace-Crabbe. Cambridge, MA: Harvard University Committee on Australian Studies, 2004.

10. Jackson, H. J. Marginalia: Readers Writing in Books. New Haven, CT: Yale University Press, 2001.

11. Stilwell, Geoffrey. "Thomas Archer." In Australian Dictionary of Biography, edited by Douglas Pike, vol. 1, pp. 25-26. Melbourne: Melbourne University Press, 1966.

12. Chick, Neil. The Archers of Van Diemens Land: A History of Pioneer Pastoral Families. Lenah Valley, Tasmania: Pedigree Press, 1991.

13. Petrow, Stefan. Going to the Mechanics: A History of the Launceston Mechanics' Institute, 1842-1914. Launceston: Historical Survey of Northern Tasmania, 1998.

14. Colclough, Stephen. "Recovering the Reader: Commonplace Books and Diaries as Sources of Reading Experience." Publishing History, no. 44 (1998): 3-13.

15. Alexander, Cynthia. "The Itinerants-a Ladies' Literary Society." Tasmanian Historical Research Association: Papers and Proceedings 32, no. 4 (December 1985): 145-52.

16. Webby, Elizabeth. "English Literature in Australia, 1840-1849." Southerly 36, no. 3 (1976): 297-317.

17. St. Clair, William. The Reading Nation in the Romantic Period. Cambridge: Cambridge University Press, 2004.

18. Scott, Sir Walter. Waverley; or 'Tis Sixty Years Since. Edited by Claire Lamont. Oxford: Oxford University Press, 1998. 